\title{
Timing of pubertal stages and breast cancer risk: the Breakthrough Generations Study
}

\author{
Danielle H Bodicoat ${ }^{1,2,6^{*}}$, Minouk J Schoemaker ${ }^{1}$, Michael E Jones ${ }^{1}$, Emily McFadden ${ }^{1,3}$, James Griffin ${ }^{1}$, \\ Alan Ashworth ${ }^{4,5}$ and Anthony J Swerdlow ${ }^{1,5}$
}

\begin{abstract}
Introduction: Breast development and hormonal changes at puberty might affect breast cancer risk, but epidemiological analyses have focussed largely on age at menarche and not at other pubertal stages.
\end{abstract}

Methods: We investigated associations between the timing of pubertal stages and breast cancer risk using data from a cohort study of 104,931 women (Breakthrough Generations Study, UK, 2003-2013). Pubertal variables were reported retrospectively at baseline. Breast cancer risk was analysed using Cox regression models with breast cancer diagnosis as the outcome of interest, attained age as the underlying time variable, and adjustment for potentially confounding variables.

Results: During follow-up (mean $=4.1$ years), 1094 breast cancers (including ductal carcinoma in situ) occurred. An increased breast cancer risk was associated with earlier thelarche (age when breast growth begins; HR [95\% Cl] $=1.23$ $[1.02,1.48], 1$ [referent] and $0.80[0.69,0.93]$ for $\leq 10,11-12$ and $\geq 13$ years respectively), menarche (initiation of menses; $1.06[0.93,1.21], 1$ [referent] and $0.78[0.62,0.99]$ for $\leq 12,13-14$ and $\geq 15$ years), regular periods $(0.99[0.83,1.18], 1$ [referent] and $0.74[0.59,0.92]$ for $\leq 12,13-14$ and $\geq 15$ years $)$ and age reached adult height $(1.25[1.03,1.52], 1$ [referent] and $1.07[0.87,1.32]$ for $\leq 14,15-16$ and $\geq 17$ years), and with increased time between thelarche and menarche $(0.87[0.65,1.15], 1$ [referent], 1.14 [0.96, 1.34] and $1.27[1.04,1.55]$ for $<0,0,1$ and $\geq 2$ years), and shorter time between menarche and regular periods (1 [referent], $0.87[0.73,1.04]$ and $0.66[0.50,0.88]$ for 0,1 and $\geq 2$ years). These associations were generally similar when considered separately for premenopausal and postmenopausal breast cancer.

Conclusions: Breast duct development may be a time of heightened susceptibility to risk of carcinogenesis, and greater attention needs to be given to the relation of breast cancer risk to the different stages of puberty.

\section{Introduction}

Breast cancer is the most common invasive cancer among women world-wide [1]. Timing of puberty is a potentially important risk factor for this tumour, in terms of breast growth and the large hormonal changes that occur around that time. There are several stages of puberty, but epidemiological analyses of breast cancer risk have focussed largely on age at menarche, perhaps because it can be most readily recalled with reasonable accuracy [2]. The stages of puberty, as outlined by Tanner, are thelarche (the start of breast growth), pubarche (the start of pubic hair growth), peak growth (an acceleration of linear growth)

\footnotetext{
* Correspondence: dhm6@le.ac.uk

${ }^{1}$ Division of Genetics and Epidemiology, Institute of Cancer Research, Sutton, UK ²Diabetes Research Centre, University of Leicester, Leicester, UK

Full list of author information is available at the end of the article
}

and menarche (first menses) [3]. Pubertal phases relevant to breast growth are thelarche, when growth begins, and menarche, when it accelerates [4]; pubertal hormonal surges are detectable by peak growth and the start of menstruation.

Menarcheal age is a well-established breast cancer risk factor [5], with an estimated 10\% reduction in breast cancer risk for each two-year increase in age at menarche [6]. Additionally, there is limited evidence indicating higher breast cancer risk in women whose menses become regular sooner, rather than later, after menarche $[7,8]$. Aside from age at menarche and onset of regular menses, the other Tanner stages have been little studied in relation to breast cancer risk. There is weak evidence that earlier peak growth might increase breast cancer

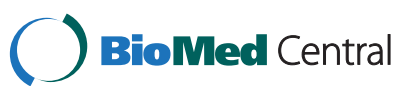


risk [9], but data are minimal, and there appear to have been no studies of risk by age at thelarche.

We, therefore, investigated the associations of age at various pubertal stages and the duration between these stages with breast cancer risk in the Breakthrough Generations Study (BGS), a large cohort study.

\section{Methods}

\section{Subjects}

The BGS is a UK cohort study focussed on breast cancer aetiology. It has received approval from the South Thames Multicentre Research Ethics Committee and all participants gave written informed consent. All women living in the UK and aged 16 years or older were eligible to join the study. Registered supporters of the charity Breakthrough Breast Cancer were invited, and other women joined either by self-referral or by nomination from an existing participant. Over 113,000 participants were recruited between 2003 and 2013. As a requirement of study entry, all BGS participants completed a postal recruitment questionnaire, which included detailed questions about known and possible breast cancer risk factors. Participants are followed-up approximately every two and a half years, using further postal questionnaires that update the recruitment information and reports of cancer diagnoses. Follow-up is based on time since recruitment; thus, at any given time different participants are at different stages of follow-up, because recruitment occurred over 10 years. At present, up to two rounds of follow-up questionnaires have been sent to participants, depending on when they were recruited. Further details of the cohort can be found elsewhere [10].

BGS participants were potentially eligible for the current analyses if they joined the study before 1 April 2010, and thus had reached at least their first follow-up point $(N=111,344)$. Of these, 6,399 women were diagnosed with invasive or in situ breast cancer and 14 had a prophylactic bilateral mastectomy before they joined the BGS, and therefore were excluded from the analysis. This left 104,931 subjects who formed the study cohort.

\section{Variables}

Incident invasive and in situ breast cancers were identified from participants' reports in the follow-up questionnaires and spontaneous reports to the study centre, and from flagging at the NHS Central Registers - virtually complete registers of the populations of England and Wales, and of Scotland, on which deaths and cancer registrations are 'flagged' and then reported to authorised medical researchers. For a total of $99 \%$ (1,082 out of 1,094 ) of reported cases, the diagnosis was confirmed by cancer registry data or pathology reports (95\%) or from the participant's general practitioner (4\%); the remaining
$1 \%$ were assumed to be true cases because they reported appropriate treatment for breast cancer.

The explanatory and confounding variables analysed were from self-reported data on the recruitment questionnaire. The explanatory variables were age at thelarche, age at menarche, age at regular periods, age when reached adult height, the intervals between these ages, and growth spurt in height between ages 7 and 11 years (as a proxy for peak growth). Age at regular periods was only analysed for women who indicated that their periods had become regular naturally rather than as a consequence of oral contraceptives or some other cause. All ages were reported to the last completed year. Information about height in childhood was collected as self-reported height relative to other girls of the same age, in five categories. Subjects were classed as having had a growth spurt between ages 7 and 11 years if their height compared with girls of a similar age increased by at least one category from age 7 to 11 .

The potential confounding variables analysed were age at recruitment (years, continuous), menopausal status (postmenopausal, premenopausal), family history of breast cancer in a first-degree relative (yes, no), adult height (centimetres, continuous), age at first full-term pregnancy ( $\leq 24$ years, 25 to 29 years, $\geq 30$ years, nulliparous), and hormone replacement therapy (HRT) use (yes, no). These variables were selected as they are breast cancer risk factors and, in exploratory analyses, affected the relationship between at least one of the explanatory variables and breast cancer risk. Adjustments for ethnicity and socioeconomic status, (based on place of residence (Acorn scores [11])), were also made, but these had no effect on the results and have not been included in the results presented.

\section{Statistical analysis}

The data were analysed using survival analysis methods. Subjects contributed person-time from recruitment into the BGS until the earliest of: end of follow-up period, diagnosis of invasive or in situ breast cancer, death, emigration from the UK or loss to follow-up. The follow-up period was based on the date of the second follow-up questionnaire for the 49,880 women who joined the study before 1 July 2006, and on the date of the first follow-up questionnaire for the remaining women. Participants who were lost to questionnaire follow-up were flagged with the NHS Central Registers, if they had agreed to this. If flagged, they were then censored at 31 December 2010 because national cancer incidence data are currently incomplete after that date; otherwise, they were censored at loss to follow-up.

Cox regression models were fitted in Stata 10.1 (StataCorp, College Station, Texas, USA) [12] with attained age as the underlying time variable, invasive or in situ breast 
cancer diagnosis as the event of interest, and all other outcomes censored. The validity of the proportional hazards assumption was assessed for each model. The initial models were unadjusted but accounted for age, because it was the underlying time variable, and menopausal status, as time at risk was stratified by menopausal status (pre- and post-menopausal). Also analyses were conducted separately for these two menopause categories as pre- and postmenopausal breast cancer have been shown to have different aetiologies to some extent [13]. Menopausal status was based on recruitment questionnaire and subsequently updated from follow-up questionnaires. The date at which a participant became post-menopausal was determined by her reported age at natural menopause or bilateral oophorectomy, or if these were unknown (for example, because of hysterectomy, or hormonal contraceptive or HRT use) at age 50 or the age at which she was last known to be premenopausal, whichever was later. Additional models were fitted that additionally adjusted for family history of breast cancer, adult height, age at first full-term pregnancy and HRT use. These are the results described in the text unless otherwise specified, since both the unadjusted and adjusted findings were very similar. Missing data were not imputed.

Sensitivity analyses were performed by repeating the analyses in various subgroups: women who were younger than age 60 years at recruitment, because recall might be better in these women; after exclusion of women who had a younger first-degree relative in the BGS because of potential correlation within pairs; and taking only invasive or in situ breast cancers as the outcome of interest in turn. Receptor status was known for too few women to allow analyses to be split by this factor.

\section{Results}

Table 1 shows descriptive characteristics of the 104,931 BGS participants who formed the cohort analysed. The subjects were aged 16 to 98 years at recruitment $($ mean $=$ 46.7 years; median $=47$ years), and the vast majority were of white ethnicity (98.8\%).

During follow-up (average follow-up $=4.05$ years, total person-years $=424,262), 1,094(1.0 \%)$ women in the cohort were diagnosed with invasive $(965 ; 88.2 \%)$ or in situ $(129 ; 11.8 \%)$ breast cancer, $20(0.02 \%)$ had a prophylactic bilateral mastectomy, 349 (0.3\%) died, and 99,545 (94.9\%) were followed to the end of their follow-up period. Of the remaining 3,924 (3.7\%), 3,240 (3.1\%) were followed to December 2010 by flagging, $423(0.4)$ were censored at emigration and $261(0.3 \%)$ were lost to follow-up.

Table 2 presents the risk of breast cancer by pubertal factors. An earlier thelarche was associated with higher breast cancer risk; women with a reported age at thelarche $\leq 10$ years had approximately $20 \%$ higher risk of breast cancer than those who reported an age at
Table 1 Baseline characteristics of cohort participants

\begin{tabular}{|c|c|}
\hline Variable & Mean [SD] or N (\%) \\
\hline Age at recruitment, years & $46.7[13.4]$ \\
\hline Average person-time, years & $4.1[1.7]$ \\
\hline Adult height, $\mathrm{cm}$ & $164.3[6.6]$ \\
\hline \multicolumn{2}{|l|}{ Menopausal status } \\
\hline Postmenopausal & $44,373(42.3)$ \\
\hline Premenopausal & $60,534(57.7)$ \\
\hline Never periods & $24(0.0)$ \\
\hline \multicolumn{2}{|l|}{ Family history of breast cancer } \\
\hline No & $89,069(84.9)$ \\
\hline Yes & $15,862(15.1)$ \\
\hline \multicolumn{2}{|c|}{ Age at first full-term pregnancy, years } \\
\hline$\leq 24$ & $25,700(24.5)$ \\
\hline 25 to 29 & $31,104(29.6)$ \\
\hline$\geq 30$ & $19,285(18.4)$ \\
\hline Parous; age not reported & $166(0.2)$ \\
\hline Nulliparous & $28,513(27.2)$ \\
\hline Parity missing & $163(0.2)$ \\
\hline \multicolumn{2}{|l|}{ Ethnicity } \\
\hline White & $103,655(98.8)$ \\
\hline Mixed white/non-white & $585(0.5)$ \\
\hline Non-white & $611(0.6)$ \\
\hline Missing & $80(0.1)$ \\
\hline \multicolumn{2}{|l|}{ Socio-economic status ${ }^{a}$} \\
\hline 1 (Highest) & $47,952(45.7)$ \\
\hline 2 & $12,001(11.4)$ \\
\hline 3 & $29,886(28.5)$ \\
\hline 4 & $8,449(8.0)$ \\
\hline 5 (Lowest) & $6,042(5.8)$ \\
\hline Channel islands/isle of man ${ }^{b}$ & $497(0.5)$ \\
\hline Unclassified & $104(0.1)$ \\
\hline Total & $104,931(100.0)$ \\
\hline
\end{tabular}

SD, Standard deviation.

a Socio-economic status was based on placed of residence (Acorn scores). ${ }^{\mathrm{b}}$ Residence-based socio-economic status not classifiable.

thelarche between 11 and 12 years $(\mathrm{HR}=1.23(95 \% \mathrm{CI}=$ $1.02,1.48)$ ). Similarly, thelarche at age 13 years or older was associated with a $20 \%$ lower risk of breast cancer $(0.80(0.69,0.93))$. A lower risk of breast cancer was also seen in women whose menarche $(0.78(0.62,0.99))$ or regular periods $(0.74(0.59,0.92))$ onset at 15 years or older compared with age 13 to 14 years, but onset at 12 years or younger was not associated with an increased risk. Conversely, women who reached their adult height at a younger age had an increased risk $(1.25(1.03,1.52))$, but reaching it at an older age ( $\geq 17$ years) was not 
Table 2 Risk of invasive or in situ breast cancer in relation to pubertal variables

\begin{tabular}{|c|c|c|c|c|c|c|}
\hline \multirow[b]{2}{*}{ Pubertal variable } & \multicolumn{3}{|c|}{ Adjusted for attained age } & \multicolumn{3}{|c|}{ Multivariate-adjusted $^{a}$} \\
\hline & $N$ cases/person-years & HR $(95 \% \mathrm{Cl})$ & & $N$ cases/person-years & HR $(95 \% \mathrm{Cl})$ & \\
\hline \multicolumn{7}{|c|}{ Age at thelarche, years } \\
\hline$\leq 10$ & $152 / 53,916$ & $1.22(1.02,1.47)$ & $*$ & $151 / 53,308$ & $1.23(1.02,1.48)$ & * \\
\hline 11 to 12 & $445 / 17,5791$ & Referent & & $443 / 173,413$ & Referent & \\
\hline$\geq 13$ & $276 / 120,309$ & $0.82(0.71,0.96)$ & $*$ & $269 / 118,581$ & $0.80(0.69,0.93)$ & $* *$ \\
\hline HR for trend & & $0.82(0.74,0.90)$ & $* * *$ & & $0.81(0.73,0.89)$ & $* * *$ \\
\hline \multicolumn{7}{|c|}{ Age at menarche, years } \\
\hline$\leq 12$ & $451 / 171,139$ & $1.03(0.90,1.17)$ & & $449 / 168,478$ & $1.06(0.93,1.21)$ & \\
\hline 13 to 14 & $449 / 171,466$ & Referent & & $444 / 168,733$ & Referent & \\
\hline$\geq 15$ & $86 / 38,779$ & $0.81(0.64,1.02)$ & & $83 / 38,109$ & $0.78(0.62,0.99)$ & * \\
\hline HR for trend & & $0.92(0.83,1.01)$ & & & $0.89(0.81,0.99)$ & * \\
\hline \multicolumn{7}{|c|}{ Age at regular periods, years } \\
\hline$\leq 12$ & $213 / 80,631$ & $0.97(0.81,1.15)$ & & $212 / 79,450$ & $0.99(0.83,1.18)$ & \\
\hline 13 to 14 & $295 / 107,008$ & Referent & & $292 / 105,314$ & Referent & \\
\hline$\geq 15$ & $105 / 50,215$ & $0.74(0.59,0.93)$ & $* *$ & $104 / 49,465$ & $0.74(0.59,0.92)$ & $* *$ \\
\hline Never had & $73 / 26,114$ & $1.15(0.89,1.49)$ & & $73 / 25,581$ & $1.16(0.90,1.50)$ & \\
\hline \multicolumn{7}{|l|}{ regular periods } \\
\hline HR for trend ${ }^{\mathrm{b}}$ & & $0.90(0.81,1.00)$ & & & $0.88(0.79,0.98)$ & * \\
\hline \multicolumn{7}{|c|}{ Age reached adult height, years } \\
\hline$\leq 14$ & $198 / 73,048$ & $1.20(0.99,1.45)$ & & $198 / 72,430$ & $1.25(1.03,1.52)$ & * \\
\hline 15 to 16 & $212 / 100,038$ & Referent & & $208 / 98,651$ & Referent & \\
\hline$\geq 17$ & $148 / 69,134$ & $1.06(0.86,1.31)$ & & $148 / 67,894$ & $1.07(0.87,1.32)$ & \\
\hline HR for trend & & $0.93(0.84,1.04)$ & & & $0.92(0.82,1.02)$ & \\
\hline \multicolumn{7}{|c|}{ Growth spurt between ages 7 and 11 years ${ }^{c}$} \\
\hline No & $956 / 37,8071$ & Referent & & $947 / 372,171$ & Referent & \\
\hline Yes & $100 / 34,784$ & $1.15(0.94,1.41)$ & & $98 / 34,259$ & $1.12(0.91,1.38)$ & \\
\hline
\end{tabular}

$\mathrm{Cl}$,Confidence interval; $\mathrm{HR}$, Hazard ratio.

${ }^{*} P<0.05$; ${ }^{* *} P<0.01 ;{ }^{* * *} P<0.001$.

${ }^{a}$ Adjusted for attained age, menopausal status, family history of breast cancer in a first-degree relative, adult height, age at first full-term pregnancy (with a term for nulliparous women) and HRT status.

${ }^{\mathrm{b}}$ Test for trend excludes those who had never had a regular period.

'Subjects were classed as having had a growth spurt between ages 7 and 11 years if their height compared with girls of a similar age increased by at least one category from age 7 to 11 .

protective. Breast cancer risk was not significantly associated with having a linear growth spurt between ages 7 and 11.

Table 3 shows the risk of invasive or in situ breast cancer by the duration between pubertal events. Breast cancer risk increased as the time between thelarche and menarche increased, but was only significant in those whose menarche occurred at least two years after the onset of thelarche $(1.27(1.04,1.55))$. Breast cancer risk also increased as the time between menarche and regular periods decreased, but again was only significant when the time between the two events was at least two years $(0.66(0.50,0.88))$. Breast cancer risk was not significantly associated with the time between thelarche and onset of regular periods, or between menarche and attaining adult height.

For premenopausal and postmenopausal breast cancer analysed separately (Additional file 1: Tables S1 and S2) and in sensitivity analyses (Additional file 1: Tables S3 and S4), the overall findings were similar to the main results in terms of the effect sizes and general pattern of results. Results for invasive and in situ breast cancers were broadly similar with no significant differences.

\section{Discussion}

Increased breast cancer risk was associated with an earlier thelarche, earlier menarche, earlier regular periods, a longer time between thelarche and menarche, or a shorter 
Table 3 Risk of invasive or in situ breast cancer in relation to duration between pubertal events

\begin{tabular}{|c|c|c|c|c|c|c|}
\hline \multirow[b]{2}{*}{ Pubertal variable } & \multicolumn{3}{|c|}{ Adjusted for attained age } & \multicolumn{3}{|c|}{ Multivariate-adjusted $^{a}$} \\
\hline & $N$ cases/person-years & HR $(95 \% \mathrm{Cl})$ & & $N$ cases/person-years & HR $(95 \% \mathrm{Cl})$ & \\
\hline \multicolumn{7}{|c|}{ Thelarche to menarche, years } \\
\hline$<0$ & $57 / 27,759$ & $0.85(0.64,1.13)$ & & $57 / 27,381$ & $0.87(0.65,1.15)$ & \\
\hline 0 & $275 / 112,810$ & Referent & & $271 / 111,168$ & Referent & \\
\hline 1 & $303 / 116,433$ & $1.14(0.97,1.34)$ & & 299/114,967 & $1.14(0.96,1.34)$ & \\
\hline$\geq 2$ & $156 / 61,061$ & $1.27(1.05,1.55)$ & * & $155 / 60,301$ & $1.27(1.04,1.55)$ & * \\
\hline$P$ for trend & & $1.14(1.05,1.23)$ & $* *$ & & $1.13(1.05,1.23)$ & ** \\
\hline \multicolumn{7}{|c|}{ Thelarche to regular periods, years } \\
\hline$<0$ & $24 / 9,864$ & $0.88(0.57,1.36)$ & & $24 / 9,734$ & $0.89(0.58,1.38)$ & \\
\hline 0 & $129 / 46,383$ & Referent & & $127 / 45,750$ & Referent & \\
\hline 1 & $179 / 71,457$ & $0.93(0.74,1.16)$ & & $177 / 70,595$ & $0.92(0.73,1.15)$ & \\
\hline$\geq 2$ & $188 / 81,162$ & $0.94(0.75,1.18)$ & & $187 / 80,149$ & $0.93(0.74,1.16)$ & \\
\hline Never became & $73 / 26,114$ & $1.19(0.89,1.59)$ & & $73 / 25,581$ & $1.19(0.89,1.58)$ & \\
\hline \multicolumn{7}{|l|}{ regular } \\
\hline$P$ for trend ${ }^{b}$ & & $0.99(0.90,1.09)$ & & & $0.98(0.89,1.08)$ & \\
\hline \multicolumn{7}{|c|}{ Menarche to regular periods, years } \\
\hline 0 & $379 / 134,744$ & Referent & & $376 / 132,702$ & Referent & \\
\hline 1 & $180 / 71,866$ & $0.88(0.74,1.06)$ & & $178 / 70,749$ & $0.87(0.73,1.04)$ & \\
\hline$\geq 2$ & $54 / 31,244$ & $0.67(0.51,0.90)$ & $* *$ & $54 / 30,778$ & $0.66(0.50,0.88)$ & ** \\
\hline Never became & $73 / 26,114$ & $1.14(0.89,1.47)$ & & $73 / 25,581$ & $1.13(0.88,1.46)$ & \\
\hline \multicolumn{7}{|l|}{ regular } \\
\hline$P$ for trend ${ }^{b}$ & & $0.84(0.75,0.95)$ & $* *$ & & $0.84(0.74,0.94)$ & ** \\
\hline \multicolumn{6}{|c|}{ Menarche to adult height, years } & \\
\hline$<0$ & $14 / 5,941$ & $0.90(0.52,1.56)$ & & $14 / 5,871$ & $0.90(0.52,1.57)$ & \\
\hline 0 to 1 & $131 / 50,937$ & Referent & & $130 / 50,492$ & Referent & \\
\hline $2-3$ & $191 / 83,968$ & $0.98(0.79,1.23)$ & & 189/82,911 & $0.96(0.77,1.21)$ & \\
\hline$\geq 4$ & $165 / 78,925$ & $0.94(0.75,1.19)$ & & $165 / 77,560$ & $0.94(0.75,1.19)$ & \\
\hline$P$ for trend & & $0.98(0.89,1.09)$ & & & $0.98(0.88,1.09)$ & \\
\hline
\end{tabular}

$\mathrm{Cl}$, Confidence interval; $\mathrm{HR}$, Hazard ratio.

${ }^{*} P<0.05$; **P $<0.01$; *** $P<0.001$.

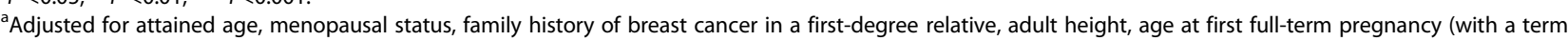
for nulliparous women) and HRT status.

${ }^{\mathrm{b}}$ Test for trend excludes those who had never had a regular period.

time between menarche and the onset of regular periods. Findings were generally similar when premenopausal and postmenopausal breast cancer were analysed separately and in sensitivity analyses.

There is evidence that breast cancer aetiology comprises several pathways, some of which have their origins early in life $[14,15]$. It has been postulated that a larger number of undifferentiated cells in the breast might increase breast cancer risk [14,15], because undifferentiated cells appear to be more liable to undergo malignant transformation than differentiated cells, based on epidemiological [14] and rat [16] studies. Another postulated pathway relates to hormones, such as oestrogen, that increase cell proliferation, thereby increasing the chance of harmful mutations occurring during DNA replication. These pathways suggest that the timing of puberty could potentially affect breast cancer risk because the number of undifferentiated breast cells increases rapidly during puberty [16] and it is a time of substantial changes in the hormonal environment [17].

Thelarche marks the start of pubertal breast growth after a period of relatively few changes during childhood [16]. Our findings provided evidence that earlier thelarche may be associated with a higher risk of breast cancer. We can find no previous data on the effects of age at thelarche on breast cancer risk [18]. There are plausible biological mechanisms by which early thelarche might increase risk. At puberty, breast ducts begin to 
grow and divide, and the ends of the ducts form terminal end buds [16]. The breast comprises predominantly undifferentiated, proliferating cells until the first full-term pregnancy and lactation, at which point a large proportion of breast cells differentiate fully [16]. Therefore, an earlier thelarche might suggest a longer time during which the breast comprises a high number of undifferentiated cells and thus has a higher risk of harmful mutations developing $[14,15]$, particularly among women who have the same age at first full-term pregnancy.

Menarche also marks a key stage of breast development. At menarche, the rate at which breast ducts grow and divide increases [19]. Early menarche is a wellestablished breast cancer risk factor [6,20,21] with our estimated HRs broadly consistent with those seen in the literature [6]. The effect of early menarche might be due to oestrogens, because they increase breast cell proliferation [22] and have been related to breast cancer risk [23], to a larger number of undifferentiated cells due to increased mammary gland size after menarche, and/or to a potentially longer time when the breast is largely undifferentiated among women with a similar age at first pregnancy.

A longer duration from thelarche to menarche also appeared to increase breast cancer risk independently of the effect of age at thelarche in regression analyses when age at thelarche was included as a potential confounder. This does not seem to have been investigated previously. However, the period between thelarche and menarche is when breast duct development largely happens, so if cells are more susceptible when in the ductal growth phase, one might expect such an association with duration from thelarche to menarche. In the context of radiation-induced breast cancer, at least, there is clear evidence that the breast is more susceptible to a carcinogenic exposure around the time of puberty than at other times [24].

Some [7,8], but not all [25], studies have found a higher risk of breast cancer among women whose menses became regular soon after menarche compared with those whose menses took longer to regulate or never became regular. We found evidence to support this. It has been suggested that women who have irregular cycles have a reduced breast cancer risk because levels of ovarian hormones are highest during the luteal phase of the menstrual cycle and women with irregular cycles would spend relatively less time in this phase than women who have regular cycles [7]. This would suggest that age at regular cycles would be associated with breast cancer risk, not just time to regular cycles, which was the case in our study in most, but not all, analyses.

Existing evidence suggests that rapid growth in childhood and adolescence may increase breast cancer risk $[26,27]$. In the BGS, we did not find this in analyses in which we estimated height velocity between ages 7 and 11 years by comparing categories of relative height at these ages. Although these were comparative data based on recall, some BGS participants $(N=199)$ reported their absolute height at these ages because they or their parents had kept records. Based on these recorded data, the average increase in height from age 7 to 11 was 26.8 $\mathrm{cm}$ in the growth spurt group and $23.4 \mathrm{~cm}$ among participants who were not classed as having had a growth spurt ( $P<0.01$ for difference), suggesting that our growth spurt measure was a reasonable proxy.

It is also of interest whether the timing of the growth spurt affects breast cancer risk. The age at peak growth is one year earlier than menarche on average [28] and was associated with increased breast cancer risk in a large Danish study [20]. Age at which adult height was reached is correlated with age at peak growth $[29,30]$ and, unlike age at peak growth, it can be ascertained by recall. Generally, studies have found that older age at attained height, and thus presumptively older age at peak growth, is associated with a lower breast cancer risk $[29,31]$, but no such association was present in the Nurses' Health Study II [30]. Our data gave limited support: although no association was found in participants overall, there was an association among women aged 60 years or younger at recruitment, whose recall might be better.

The timing of pubertal events is likely to be correlated to some extent, which may partly explain our findings and the fact that many of the effect sizes were similar

Table 4 Correlations between timing of pubertal variables

\begin{tabular}{|c|c|c|c|c|c|c|c|}
\hline & Thelarche & Menarche & $\begin{array}{l}\text { Regular } \\
\text { periods }\end{array}$ & $\begin{array}{l}\text { Reached adult } \\
\text { height }\end{array}$ & $\begin{array}{l}\text { Thelarche to } \\
\text { menarche }\end{array}$ & $\begin{array}{l}\text { Thelarche to } \\
\text { regular periods }\end{array}$ & $\begin{array}{l}\text { Menarche to } \\
\text { regular periods }\end{array}$ \\
\hline Menarche & 0.02 & & & & & & \\
\hline Regular periods & 0.02 & 0.58 & & & & & \\
\hline Reached adult height & 0.00 & 0.34 & 0.22 & & & & \\
\hline Thelarche to menarche & 0.00 & -0.01 & 0.81 & 0.03 & & & \\
\hline Thelarche to regular periods & -1.00 & -0.02 & -0.01 & -0.00 & -0.00 & & \\
\hline Menarche to regular periods & -1.00 & -0.02 & -0.01 & -0.00 & 0.01 & 1.00 & \\
\hline Menarche to adult height & -0.01 & -0.36 & -0.19 & 0.75 & 0.03 & 0.01 & 0.01 \\
\hline
\end{tabular}


across pubertal events. However, Table 4 shows that the correlation between event timing was low in most instances. Interestingly, the duration between thelarche and menarche was not correlated with age at thelarche or age at menarche, but was highly correlated with age at regular periods. Likewise, age at thelarche was highly correlated with time between menarche and regular periods, but not with age at menarche or age at regular periods. These high correlations suggest that these risk factors may be acting through the same pathway as each other or one may be a marker for the other.

These analyses included comprehensive adjustment for potential confounders. While benign breast disease is an established risk factor for breast cancer, we did not adjust for it as it is unlikely to be a confounder of the relationship between puberty variables and breast cancer. It is possible that benign breast disease is on the same causal pathway and is a mediator of the relationship between pubertal variables and breast cancer risk, though evidence linking pubertal factors to benign breast disease is lacking.

The pubertal variables that we analysed were reported retrospectively; therefore their accuracy should be considered. Whereas menarche is a well-defined single event that women can recall with reasonable accuracy (for example, $90 \%$ accurately recalled the age within a year in one study [2]), the onset of breast development, regular menses and peak growth cannot be ascertained by a single event and, hence, recall is likely to be less accurate. There is some evidence of this inaccuracy for regular menses $[2,32]$, but the validity of recalled age at thelarche does not appear to have been studied previously and we had to rely on proxies for age at peak growth. However, the timing of pubertal stages was reported at baseline before breast cancer diagnosis and so it is unlikely that recall of the pubertal stages would be biased with respect to a subsequent breast cancer diagnosis. Thus, the likely effect of inaccurate recall would have been to attenuate any true associations.

Another limitation of the present analyses is that the average follow-up was only four years. Despite this, more than 1,000 breast cancers had occurred due to the size of the cohort. In addition to the large sample size, the other strengths of this study were its prospective nature, and that it examined several potential breast cancer risk factors for which there has been no or little existing research.

While the only inclusion criteria for women to join the BGS were that they must be aged at least 16 years and living in the UK, there are indications that the study participants are on average a somewhat high-risk population - they tend to be of higher socioeconomic status and more often to have a family history of breast cancer than the UK general population [10]. There seems no reason, however, why this should have affected the associations, as opposed to the distribution of risk factors, reported here.

\section{Conclusions}

In conclusion, the novel findings of this study are that earlier thelarche and a longer time between thelarche and menarche might increase breast cancer risk, as well as the already-investigated effects of early menarche, regular periods and the time between the two. This suggests that breast duct development may be a period of raised susceptibility to breast carcinogenesis, and that the association between puberty and breast cancer is complex and not best represented by a single event. Further research on the effects of pubertal stages other than age at menarche is needed to elucidate these relationships.

\section{Additional file}

Additional file 1: Table S1. Risk of invasive or in situ breast cancer in relation to pubertal variables, by menopausal status at breast cancer incidence. Table S2. Risk of invasive or in situ breast cancer in relation to duration between pubertal events, by menopausal status at breast cancer incidence. Table S3. Sensitivity analyses of risk of invasive or in situ breast cancer in relation to pubertal variables. Table S4. Sensitivity analyses of risk of invasive or in situ breast cancer in relation to duration between pubertal events.

\section{Abbreviations}

BGS: Breakthrough generations study; HRT: Hormone replacement therapy.

\section{Competing interests}

All authors declare that they have no competing interests.

\section{Authors' contributions}

AJS and AA are Principal Investigators of the Breakthrough Generations Study and conceived the study. All authors have contributed towards the design and data collection of the Breakthrough Generations Study. DHB conceived these analyses and planned and performed them with input from MJS, MEJ, EM and JG. DHB wrote the first draft of the manuscript and all authors contributed to data interpretation and revisions of the manuscript. All authors have approved the final version of the manuscript.

\section{Acknowledgements}

We thank the women who participated in the study, and our colleagues in the Breakthrough Generations Study Team.

This work was supported by Breakthrough Breast Cancer, the Sir John Fisher foundation and the Institute of Cancer Research. We acknowledge NHS

funding to the Royal Marsden Hospital, Institute of Cancer Research and the NIHR Biomedical Research Centre. The funders had no role in the analysis, interpretation or decision to publish these results.

\section{Author details}

'Division of Genetics and Epidemiology, Institute of Cancer Research, Sutton, UK. ${ }^{2}$ Diabetes Research Centre, University of Leicester, Leicester, UK. ${ }^{3}$ Department of Primary Care Health Sciences, Oxford University, Oxford, UK. ${ }^{4}$ Breakthrough Breast Cancer Research Centre and Division of Molecular Pathology, Institute of Cancer Research, London, UK. ${ }^{5}$ Division of Breast Cancer Research, Institute of Cancer Research, Sutton, UK. ${ }^{6}$ Diabetes Research Centre, University of Leicester, Leicester Diabetes Centre, Leicester General Hospital, Gwendolen Road, Leicester, Leicestershire LE5 4PW, UK.

Received: 23 August 2013 Accepted: 30 January 2014

Published: 4 February 2014 


\section{References}

1. Ferlay J, Shin HR, Bray F, Forman D, Mathers C, Parkin DM: Globocan 2008: Cancer Incidence and Mortality Worldwide. Lyon, France: IARC.

2. Bean JA, Leeper JD, Wallace RB, Sherman BM, Jagger H: Variations in the reporting of menstrual histories. Am J Epidemiol 1979, 109:181-185.

3. Marshall WA, Tanner JM: Variations in pattern of pubertal changes in girls. Arch Dis Child 1969, 44:291-303.

4. Russo J, Russo IH: Development of the human mammary gland. In The Mammary Gland. Development, Regulation, and Function. Edited by Neville MC, Daniel CW. New York: Plenum Press; 1987:67-93.

5. Kelsey JL, Gammon MD, John EM: Reproductive factors and breast-cancer. Epidemiol Rev 1993, 15:36-47.

6. Hsieh CC, Trichopoulos D, Katsouyanni K, Yuasa S: Age at menarche, age at menopause, height and obesity as risk factors for breast cancer: associations and interactions in an international case-control study. Int J Cancer 1990, 46:796-800.

7. Titus-Ernstoff L, Longnecker MP, Newcomb PA, Dain B, Greenberg ER, Mittendorf R, Stampfer M, Willett W: Menstrual factors in relation to breast cancer risk. Cancer Epidemiol Biomarkers Prev 1998, 7:783-789.

8. Butler LM, Potischman NA, Newman B, Millikan RC, Brogan D, Gammon MD, Swanson CA, Brinton LA: Menstrual risk factors and early-onset breast cancer. Cancer Causes Control 2000, 11:451-458.

9. Ahlgren M, Melbye M, Wohlfahrt J, Sørensen Tl: Growth patterns and the risk of breast cancer in women. N Engl J Med 2004, 351:1619-1626.

10. Swerdlow AJ, Jones ME, Schoemaker MJ, Hemming J, Thomas D, Williamson J, Ashworth A: The Breakthrough Generations Study: design of a long-term UK cohort study to investigate breast cancer aetiology. Br J Cancer 2011, 105:911-917.

11. ACORN: What is ACORN? [http://acorn.caci.co.uk]

12. StataCorp: Stata Statistical Software: Release 12. College Station, TX: StataCorp LP; 2011.

13. Clemons M, Goss P: Estrogen and the risk of breast cancer. N Engl J Med 2001, 344:276-285.

14. Trichopoulos D, Lagiou P, Adami HO: Towards an integrated model for breast cancer etiology: the crucial role of the number of mammary tissue-specific stem cells. Breast Cancer Res 2005, 7:13-17.

15. Hankinson SE, Colditz GA, Willett WC: Towards an integrated model for breast cancer etiology: the lifelong interplay of genes, lifestyle, and hormones. Breast Cancer Res 2004, 6:213-218.

16. Russo J, Russo IH: Development of the human breast. Maturitas 2004 , 49:2-15.

17. Apter D, Vihko R: Early menarche, a risk factor for breast cancer, indicates early onset of ovulatory cycles. J Clin Endocrinol Metabol 1983, 57:82-86.

18. Velie EM, Nechuta S, Osuch JR: Lifetime reproductive and anthropometric risk factors for breast cancer in postmenopausal women. In Hormones and Breast Cancer in Postmenopausal Women. Edited by Haslam SZ, Osuch JR. Amsterdam: IOS Press; 2006:17-36.

19. Colditz GA, Baer HJ, Tamimi RM: Breast cancer. In Cancer Epidemiology and Prevention. 3rd edition. Edited by Schottenfeld D, Fraumeni JF. New York: Oxford University Press; 2006:995-1012.

20. Brinton LA, Schairer C, Hoover RN, Fraumeni JF Jr: Menstrual factors and risk of breast-cancer. Cancer Investig 1988, 6:245-254.

21. La Vecchia C, Negri E, Bruzzi P, Dardanoni G, Decarli A, Franceschi S, Palli D, Talamini $R$ : The role of age at menarche and at menopause on breast cancer risk: combined evidence from four case-control studies. Ann Oncol 1992, 3:625-629.

22. Pike MC, Spicer DV, Dahmoush L, Press MF: Estrogens, progestogens, normal breast cell proliferation, and breast cancer risk. Epidemiol Rev 1993, 15:17-30.

23. The Endogenous Hormones and Breast Cancer Collaborative Group: Endogenous sex hormones and breast cancer in postmenopausal women: reanalysis of nine prospective studies. J Natl Cancer Inst 2002, 94:606-616.

24. Cooke R, Jones ME, Cunningham D, Falk SJ, Gilson D, Hancock BW, Harris SJ, Horwich A, Hoskin PJ, Illidge T, Linch DC, Lister TA, Lucraft HH, Radford JA, Stevens AM, Syndikus I, England and Wales Hodgkin Lymphoma Follow-up Group, Williams MV, Swerdlow AJ: Breast cancer risk following Hodgkin lymphoma radiotherapy in relation to menstrual and reproductive factors. Br J Cancer 2013, 108:2399-2406.
25. Rockhill B, Moorman PG, Newman B: Age at menarche, time to regular cycling, and breast cancer (North Carolina, United States). Cancer Causes Control 1998, 9:447-453.

26. De Stavola BL, dos Santos SI, McCormack V, Hardy RJ, Kuh DJ, Wadsworth ME: Childhood growth and breast cancer. Am J Epidemiol 2004, 159:671-682.

27. Berkey CS, Gardner JD, Frazier AL, Colditz GA: Relation of childhood diet and body size to menarche and adolescent growth in girls. Am J Epidemiol 2000, 152:446-452.

28. Chang SH, Tzeng SJ, Cheng JY, Chie WC: Height and weight change across menarche of schoolgirls with early menarche. Arch Pediatr Adolesc Med 2000, 154:880-884.

29. Li Cl, Littman AJ, White E: Relationship between age maximum height is attained, age at menarche, and age at first full-term birth and breast cancer risk. Cancer Epidemiol Biomarkers Prev 2007, 16:2144-2149.

30. Baer HJ, Rich-Edwards JW, Colditz GA, Hunter DJ, Willett WC, Michels KB: Adult height, age at attained height, and incidence of breast cancer in premenopausal women. Int J Cancer 2006, 119:2231-2235.

31. Li Cl, Malone KE, White E, Daling JR: Age when maximum height is reached as a risk factor for breast cancer among young US women. Epidemiology 1997, 8:559-565.

32. Must A, Phillips SM, Naumova EN, Blum M, Harris S, Dawson-Hughes B, Rand WM: Recall of early menstrual history and menarcheal body size: after 30 years, how well do women remember? Am J Epidemiol 2002, 155:672-679.

\section{doi:10.1186/bcr3613}

Cite this article as: Bodicoat et al:: Timing of pubertal stages and breast cancer risk: the Breakthrough Generations Study. Breast Cancer Research 2014 16:R18.

\section{Submit your next manuscript to BioMed Central and take full advantage of:}

- Convenient online submission

- Thorough peer review

- No space constraints or color figure charges

- Immediate publication on acceptance

- Inclusion in PubMed, CAS, Scopus and Google Scholar

- Research which is freely available for redistribution

Submit your manuscript at www.biomedcentral.com/submit
C BioMed Central 